\title{
ELECTROCHEMICAL MIGRATION IN THICK-FILM IC-S
}

\author{
GABOR RIPKA \\ Dept of Electronics Technology, Technical University, Budapest, 1521, Hungary. \\ and \\ GABOR HARSANYI \\ Enterprise for Microelectronics, Budapest, 1325 Pf. 21, Hungary. \\ (Received January 17, 1983; in final form November 1, 1983)
}

\begin{abstract}
The phenomenon of silver migration in conductor-insulator systems is well known, but it is less known that several other metals can exhibit migration. This paper tries to give a short summary of the phenomenon as applied to thick-film circuits.

Tests have been made on different conductors used in thick-film circuits. The dendrites formed by electrochemical migration were examined by scanning electron microscope, and also by wavelength-dispersive analysis of the emitted $x$-rays. By obtaining secondary and back-scattered electron images, $x$-ray maps and profiles, it can be determined which components cause migration in the conductor in question.

Photos are presented illustrating the results.

Thermal Humidity Bias test was also performed in controlled environmental chambers in order to get a comparison between different thick film systems.
\end{abstract}

\section{INTRODUCTION}

In the production of large scale thick-film ICs, the claim that conductors can be produced with very good line resolution and high reliability has been made.

When using gaps narrower than $0.2 \mathrm{~mm}$, however, reliability problems can occur. It is possible that ion migration causes resistive shorts between neighbouring metallization stripes, and this leads to the breakdown of the circuit.

After a short summary describing the basic aspects of the electro-chemical processes that cause failures, investigations on short-circuits caused by electro migration in thickfilm microcircuits using different conductor compositions are reported in this paper. The purpose was to determine how the potential reliability problems can be minimized.

\section{ELECTROCHEMICAL MIGRATION}

The essence of the phenomenon is the migration of ions in the presence of moisture under electrical bias between two electrodes. Surface migration occurs between parallel conductors and bulk migration between the electrodes of capacitors through the porous dielectric layer, or, in multilayer structures, through the holes and cracks in the insulator.

The process starts when a thin continuous liquid film of $\mathrm{H}_{2} \mathrm{O}$ (more than a few monolayers) is formed between the metallization layers, in which ions can be transported.

Chemical reaction takes place at the positively biased conductor to form positive metal ions - or cations of other types - unless a passivating metaloxide layer forms on the surface. The ions will migrate toward the cathode where they are deposited. The electric field is deformed at the micro-rough surface of the cathode, but is enhanced and the deposition is quicker at the edges. This leads to the formation of dendrites. When one of the dendrites reaches the anode, a metal bridge is formed between the conductors and an electrical short occurs. 
During the growth process, the decomposition of water also takes place, and the value of the $\mathrm{pH}$ at the anode will be decreased, therefore. This condition inhibits the formation of the passivating layer and accelerates the dissolution of the metal.

If the dendritic growth is fast, a dense jumble of dendrites can develop. The decrease of the insulation resistance causes an increase of the electric current, the heat generation leads to the boiling of the water layer and thus the dendrites will be destroyed. This is the reason why one can often observe sporadically continuous, but rough, layers instead of separate dendrites. The phenomenon of silver migration in conductor-insulator-conductor systems has often been discussed. ${ }^{1}$ Investigations over the past years have proved that other metals also exhibit this electrochemical process. ${ }^{2}$ Therefore one must reckon with migration failures even in the case of silver free metallization layers.

Migrated resistive shorts occur rarely in practice and only under extreme conditions. A device could operate for many hundreds of hours under normal operating conditions, and then after a short operational exposure to higher relative humidity, fail. If one wants to determine how the potential reliability problems can be minimized, one has to force the conductors to migrate. This needs simulated environmental conditions.

\section{EXPERIMENTAL RESULTS}

The samples were made by thick-film technology using different conductor compositions. The films were printed with a 200 mesh steel screen onto $96 \%$ alumina substrates. The layers were dried at $150^{\circ} \mathrm{C}$ for $15 \mathrm{~min}$ and fired at $85^{\circ} \mathrm{C}$ (cycle: $60 \mathrm{~min}$ ) in air using a four zone belt furnace (type, BTU-VMQ4). We used Du Pont and Remex conductor pastes. It has been found that the migration is influenced primarily by the metallic components of the conductors.

WD tests were carried out on the samples and the changes were examined by SEM and by wavelength-dispersive analysis of the emitted x-rays (EMPA).

\subsection{Silver Migration}

As has been mentioned, silver migration is an old problem in electronics. In the thickfilm ICs, lower cost Pt-Ag and Pd-Ag pastes are often used, so that silver migration may be a real problem in these circuits. The silver loaded chip attachment resins can also be sources of migration.

Figure 1 is a backscattered electron image (BEI) of two parallel Pd-Ag conductors. The width of the metallization stripes is $0.5 \mathrm{~mm}$ and the separation distance between the stripes is $0.2 \mathrm{~mm}$. The material contrast sets off the outlines of the transmigrated metal layer very well. Separate dendrites are not observable (the cause of this has been mentioned above).

Figure 2(a) is a close up of Figure 1. Figure 2(b) and 2(c) are the $x$-ray intensity maps for $\mathrm{Ag}$ and $\mathrm{Pd}$ respectively. The presence of silver in the transmigrated layer can be seen very well, but the palladium did not appear to migrate.

Silver ions dissolve at the anode and migrate toward the cathode quickly so the time to failure is short in this system. (It is $10-15 \mathrm{~s}$ through a drop of deionized water with 10 volt $\mathrm{dc}$ applied using the above-mentioned geometry). Thus the use of pure silver in thick film circuits has become infrequent. With the Pt-Ag or Pd-Ag conductors the platinum or palladium reduces the dissolution of silver, but does not appear to stop it. Recently, paste manufacturers have developed ternary Pd-Pt-Ag conductor compositions in which silver migration has been eliminated. Platinum - even in small quantities, is able to bring about a qualitative change here, although this effect cannot be observed in $\mathrm{Pd}-\mathrm{Ag}$ conductors. The reason of this phenomenon has not been understood. 


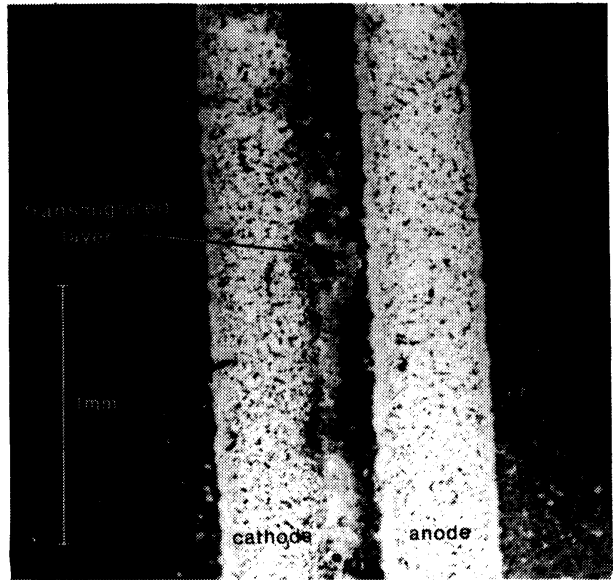

FIGURE 1 SEM photograph of two Pd-Ag conductors (BEI)
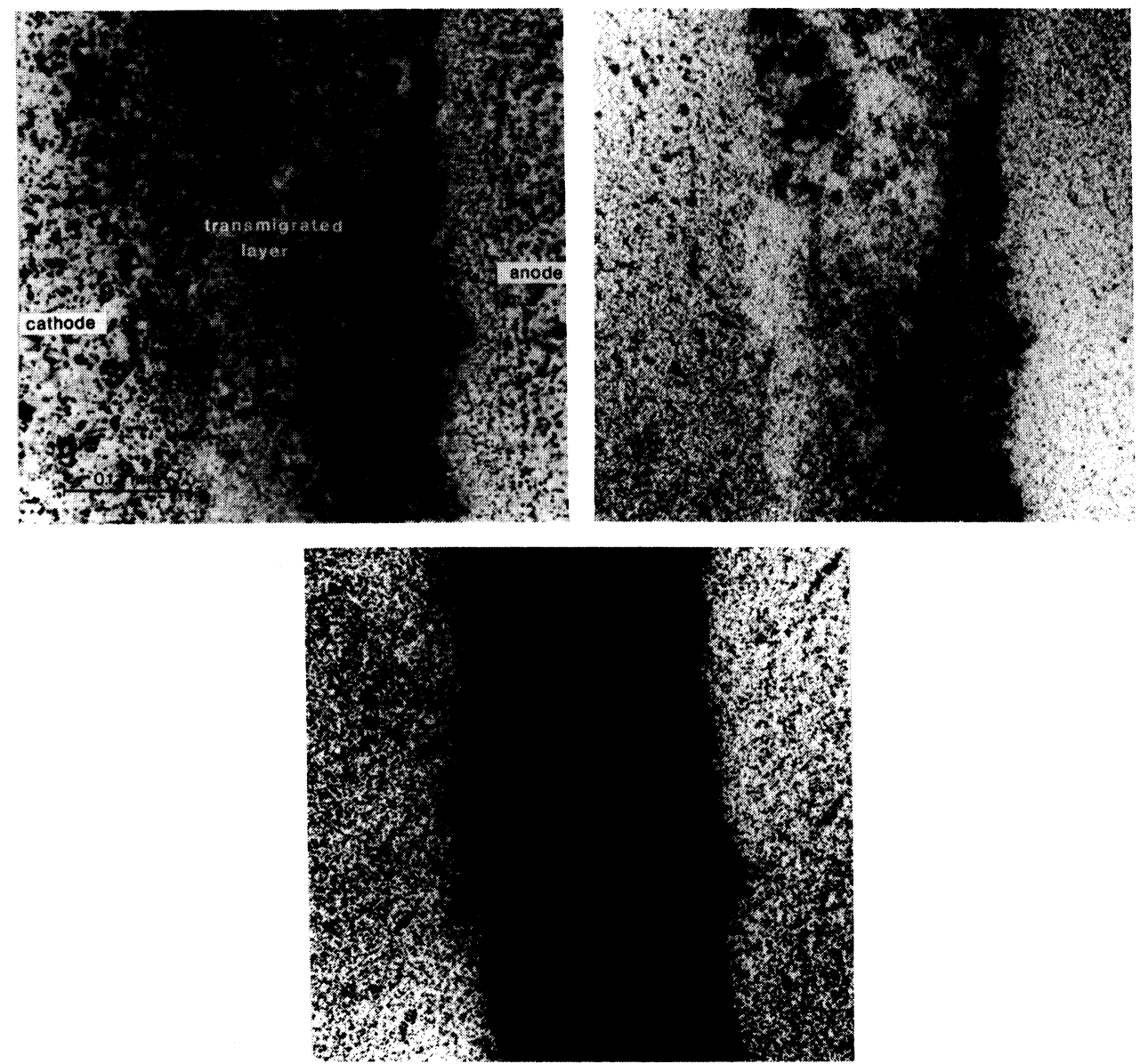

FIGURE 2 Elemental mapping between Pd-Ag conductors. (a) SEM photograph (BEI), (b) AgL , (c) $\mathrm{PdL}_{\alpha}$ 


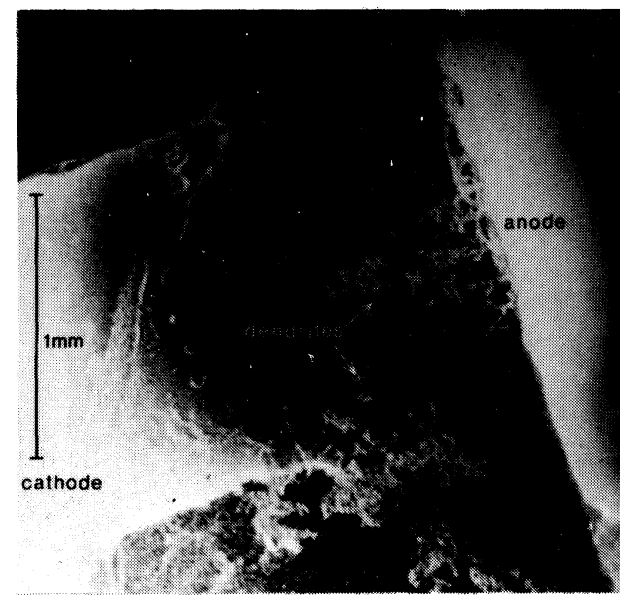

FIGURE 3 Dendrites between soldered Au-Pt conductors. (SEM photograph SEI)

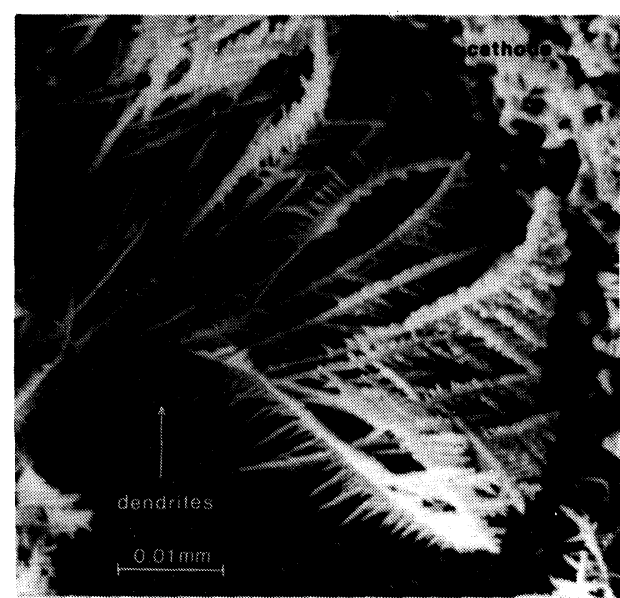

FIGURE 4 The structure of the dendrites (SEI)
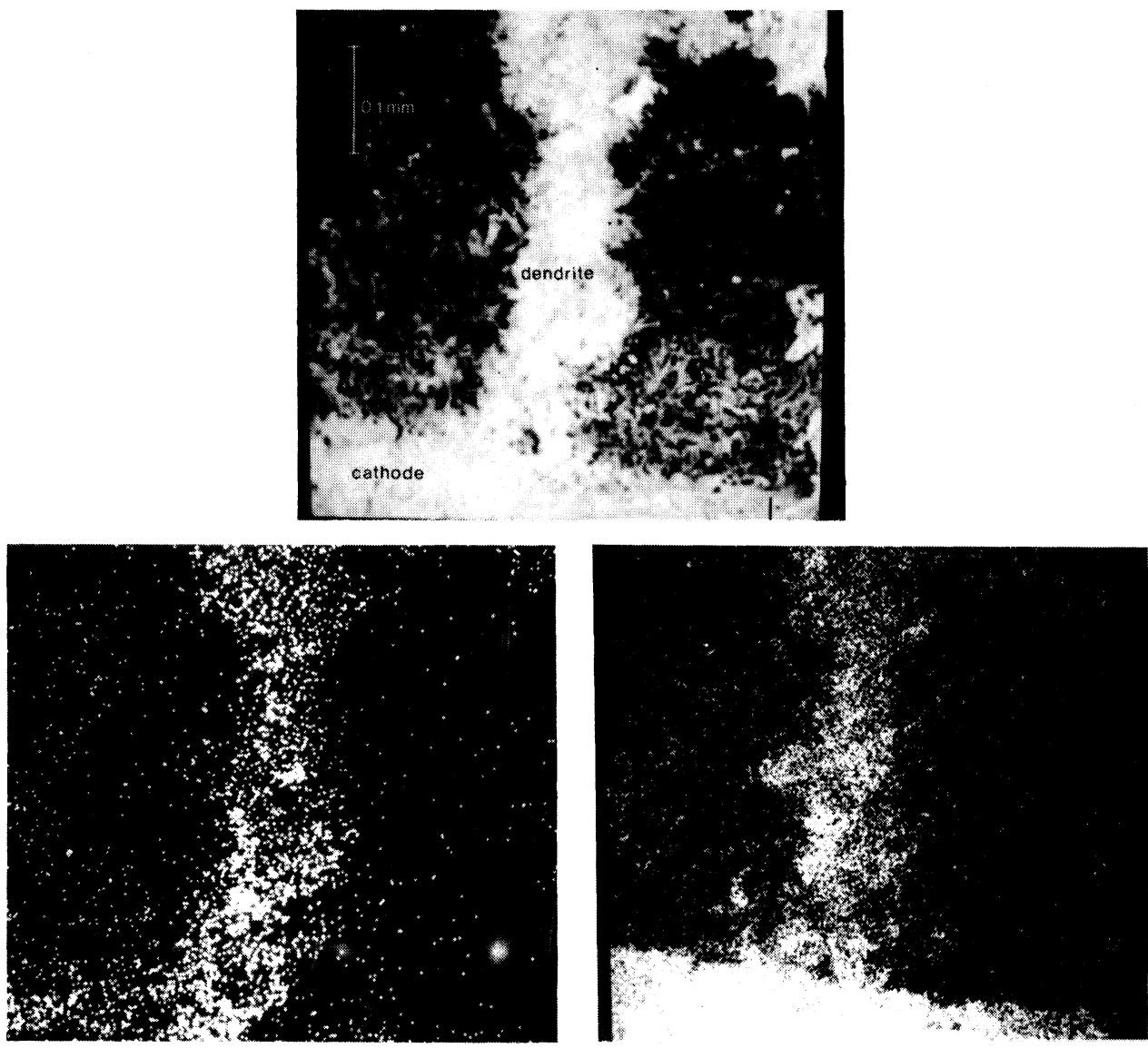

FIGURE 5 Elemental mapping of a dendrite between soldered Au-Pt conductors. (a) SEM photographs (BEI), (b) $\mathrm{PbM}_{\alpha}$, (c) $\mathrm{SnL}_{\alpha}$ 


\subsection{Tin and Lead}

Figure 3 is a SEM view of two silver free conductors covered by silver free solder. (Separation distance $0.8 \mathrm{~mm}$ ). Transmigrated dendrites are recognizable between them. Figure 4 shows the structure of the dendrites. Figure $5(\mathrm{a})$ is a close up of a dendrite.

The X-ray intensity maps of the same dendrite for $\mathrm{Pb}$ and $\mathrm{Sn}$ in Figures 5(b) and 5(c) show that both components have migrated.

Thus even in the case of silver free conductors and solders, migration can occur. This means that there can be reliability problems particularly in hybrid ICs where the encapsulated semiconductors (in SO-packages) or the other hybrid components and leads are solder mounted.

\subsection{Copper}

The recent increases in the prices of precious metals have increased the incentive to study base metals' systems, such as copper. These conductors are processable in a nitrogen atmosphere. Direct replacement of all conductors with $\mathrm{Cu}$ however is impossible because of processing, bondability and resistor-compatibility problems. The use of copper conductors will not solve the migration problem either.

Examinations have demonstrated that copper is also liable to show migration. Figure 6 is a BEI of two parallel copper conductors. The width of the stripes is $0.3 \mathrm{~mm}$, and the separation distance is $0.5 \mathrm{~mm}$. The material contrast shows the transmigrated dendrites Figure 7a is a secondary electron image (SEI) of the dendrites. Figures 7(b) and 7 (c) are the $\mathrm{x}$-ray intensity maps for $\mathrm{Cu}$ and $\mathrm{Al}$ respectively. These prove the presence of copper in the dendrites that contain a considerable quantity of the metal; thus they can absorb the $\mathrm{AlK}_{\alpha} \mathrm{X}$-ray photons emitted by the $\mathrm{Al}_{2} \mathrm{O}_{3}$ substrate. Figure 8 is an enlarged SEI of a dendrite.

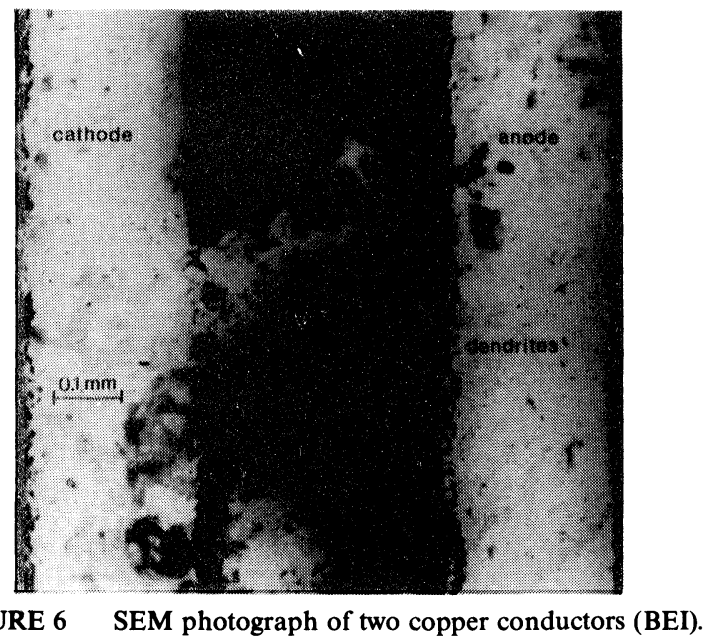

\subsection{Gold}

Even gold, which is famous for its passivity, can migrate under certain conditions. Gold migration has been reported ${ }^{3}$ when $\mathrm{Ti} / \mathrm{Pd} / \mathrm{Au}$ thin film metallization systems were examined. If the adsorbed layer of water contains $\mathrm{Cl}^{-}$ions, $(0.1$ to 0.001 molar $)$, gold will migrate. Gold dissolves at the anode in the presence of $\mathrm{Cl}^{-}$, and a soluble tetrachlorogold complex is formed, ${ }^{3}$ 

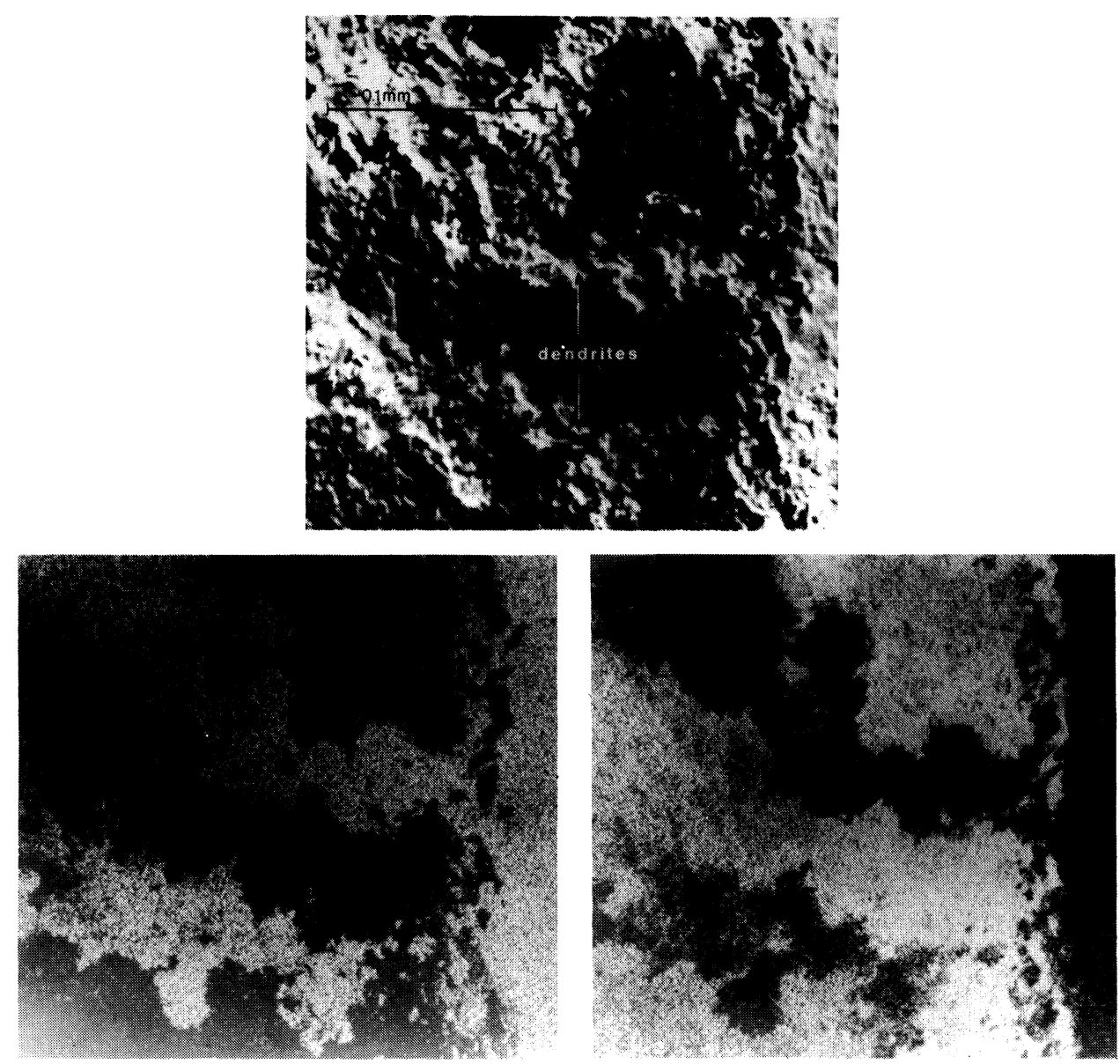

FIGURE 7 Elemental mapping of copper dendrites. (a) SEM photograph (SEI), (b) $\mathrm{CuK}_{\alpha}$, (c) $\mathrm{AlK}_{\alpha}$

$$
\mathrm{Au}+4 \mathrm{Cl}^{-} \longrightarrow \mathrm{AuCl}_{4}^{-}+3 \mathrm{e}^{-} .
$$

This complex is, however, not stable. The main forms of gold in solutions are complex ions of the type:

$$
\left[\mathrm{Au}(\mathrm{OH})_{\mathrm{x}} \mathrm{Cl}_{\mathrm{y}}\right]^{(\mathrm{x}+\mathrm{y}-3)-}(\mathrm{x}+\mathrm{y}<4) .
$$

Positive ions may also be present $(x=y=1)$ which will migrate toward the cathode. ${ }^{4}$ Classical dendritic growth is not observed although metallic extensions appear at the cathode, as can be seen in Figure 9 (SEI of two conductors after WD test using 0.1 molar $\mathrm{NaCl}$ solution. The stripes and the gap are $0.3 \mathrm{~mm}$ wide) Figure 10 (a) is an enlargement of Figure 9. The x-ray intensity map for $\mathrm{Au}$ in Figure 10(b) demonstrates the presence of gold in the extensions.

Similar extensions occur with $\mathrm{Au}-\mathrm{Pt}$ and $\mathrm{Au}-\mathrm{Pd}$ conductors and the results of the electron microprobe analysis indicate that in these cases platinum and palladium are involved in migration. 


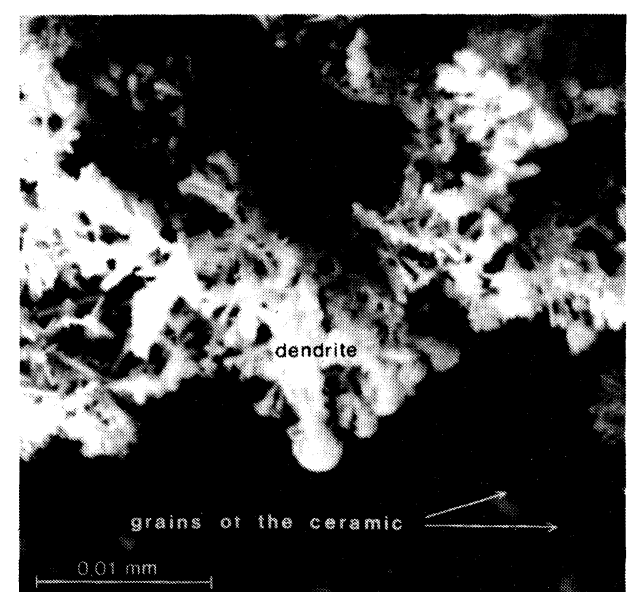

FIGURE 8 Close up of a copper dendrite.

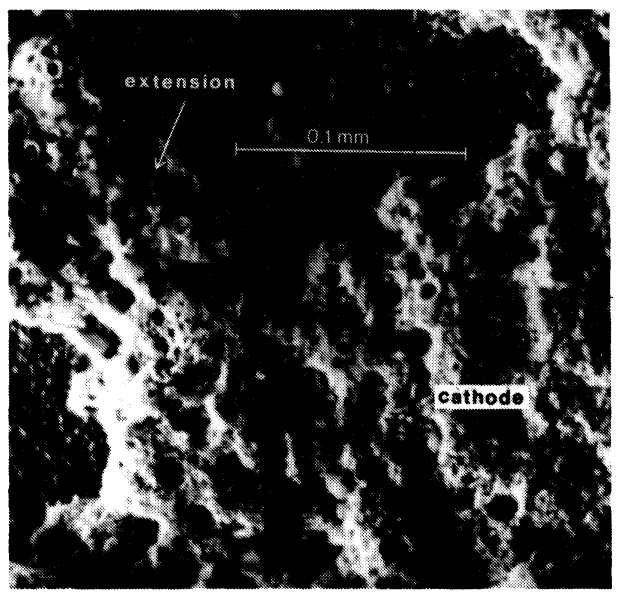

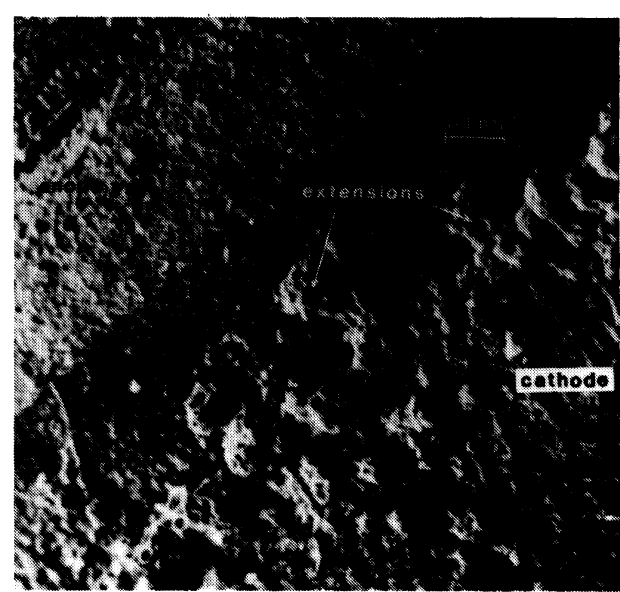

FIGURE 9 Gold migration (SEI).

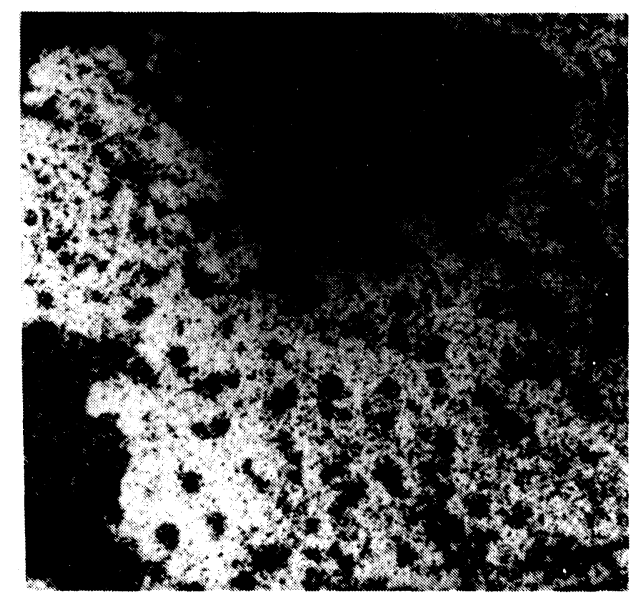

FIGURE 10 Elemental mapping of the gold conductors. (a) SEM photograph - close up of Figure 9. (b) $\operatorname{AuM}_{\alpha}$

Thus, even the use of precious metals cannot protect thick-film ICs from migration failures if the surface of the substrate is contaminated with chloride ions.

$\mathrm{Cl}^{-}$is a common contaminant on device surfaces. ${ }^{3}$ It may originate from fingerprints $(\mathrm{NaCl})$, or from the breakdown of cleaning solvent molecules e.g., trichloroethylene. Often dust particles contribute $\mathrm{Cl}$, and $\mathrm{Cl}_{2}$ in the atmosphere may also be a source of $\mathrm{Cl}^{-}$ions. Chloride is also a constituent of residual fluxes.

\subsection{Bismuth}

Examinations of electrochemical migration called attention to a phenomenon that has not been reported in any paper to date. It has been found that migrated short-circuits occur between $\mathrm{Au}-\mathrm{Pd}$ and $\mathrm{Au}-\mathrm{Pt}$ conductors on, or through, barium-titanate-insulators which are used for thick-film capacitors. There was no appreciable chloride contaminant on the samples. Even in the case of the non-migrating ternary Pd-Pt-Ag composition failures occurred. The electron microprobe analysis showed no $\mathrm{Au}, \mathrm{Pd}, \mathrm{Pt}$ or $\mathrm{Ag}$ traces between the metallization stripes. 
By studying a series of samples using different non-migrating conductors (on alumina substrates, without $\mathrm{Cl}^{-}$contamination) and a number of dielectric pastes, it proved that the dendritic growth was influenced mainly by the type of dielectric. There was a close connection between the speed of the dendritic growth and the $\mathrm{Bi}_{2} \mathrm{O}_{3}$ content of the dielectric. $\mathrm{Bi}_{2} \mathrm{O}_{3}$ is used in these pastes as an inorganic binder. X-ray diffraction and $x$-ray photoelectron spectroscopy showed the presence of bismuth metal on the samples where short-circuits had occurred.

The conclusions drawn from these results are as follows:

(a) At the cathode electrochemical reduction occurs

$$
2 \mathrm{H}^{+}+2 \mathrm{e} \longrightarrow \mathrm{H}_{2} \text {. }
$$

(b) In addition to this a chemical oxidation-reduction between the hydrogen ion and $\mathrm{Bi}_{2} \mathrm{O}_{3}$ may occur,

$$
\mathrm{Bi}_{2} \mathrm{O}_{3}+6 \mathrm{H}^{+} \longrightarrow 2 \mathrm{Bi}^{3+}+3 \mathrm{H}_{2} \mathrm{O} \text {. }
$$

(c) Bismuth ions migrate to the cathode and are deposited on the cathode,

$$
\mathrm{Bi}^{3+}+3 \mathrm{e} \longrightarrow \mathrm{Bi}
$$

(d) As deposition proceeds the ions are deposited at the tips of the dendrites.

(e) Process (b) may be aided by the porosity of the $\mathrm{BaTiO}_{3}$ ferroelectric material containing the $\mathrm{Bi}_{2} \mathrm{O}_{3}$.

Thus all thick-film capacitors are inclined to migration failures independently of the electrode material if the dielectric contains $\mathrm{Bi}_{2} \mathrm{O}_{3}$. Although $\mathrm{Bi}_{2} \mathrm{O}_{3}$ is a more favourable binder in these systems than different glasses ${ }^{3}$ it will be necessary to determine the critical bismuth-oxide content to reduce bismuth-migration.

\subsection{Thermal-Humidity-Bias (THB) Test}

THB testing was conducted on 150-150 samples for up to 4000 hours. The purpose was to estimate the average time to failure of $0.5 \mathrm{~mm} \times 4 \mathrm{~mm}$ parallel thick-film metallization stripes with a $0.2 \mathrm{~mm}$ gap size, and that of $11 \mathrm{~mm}^{2}$ area thick film capacitors (dielectric constant $\mathrm{K}=300$, fired dielectric thickness 50-60 $\mu \mathrm{m}$ ) under conditions of $95 \%$ relative humidity at $40^{\circ} \mathrm{C}$ and $10 \mathrm{~V}$ dc power loading. We applied a $1.8 \mathrm{k}$ current limiting resistor in series with each sample. A "failure" is defined here as a sample with a resistance smaller than or equal to $1 \mathrm{M} \Omega$. $\mathrm{Cl}^{-}$contaminated systems were also examined. The contamination was applied to the substrates by rinsing them in a $0.01 \mathrm{M} \mathrm{NaCl}$ solution. A silicone encapsulant (Dow Corning $36550 \mathrm{RTV}, \mathrm{RTV}=\mathrm{Room}$ Temperature Vulcanizing) has also been investigated as to its effectiveness in preventing migrated resistive shorts.

Results of the THB test are summarized in Table I. As we can see, $\mathrm{NaCl}$ contamination shortened the life time and caused resistive shorts even in the case of $\mathrm{Au}$, $\mathrm{Au}-\mathrm{Pt}, \mathrm{Au}-\mathrm{Pd}$ conductors. At the same time $\mathrm{Ag}-\mathrm{Pd}-\mathrm{Pt}$ was the most favourable compo- 
TABLE I

THB-test on different conductors (conditions: $95 \% \mathrm{RH}, 40^{\circ} \mathrm{C}, 10$ volt dc)

\begin{tabular}{lcccc}
\hline & \multicolumn{4}{c}{ Average time to failure (hours) } \\
\cline { 2 - 5 } $\begin{array}{l}\text { Conductor } \\
\text { composition }\end{array}$ & $\begin{array}{l}\text { Metallization stripes } \\
\text { contamination }\end{array}$ & $\begin{array}{l}0,01 \mathrm{M} \mathrm{NaCl} \\
\text { contamination }\end{array}$ & $\begin{array}{l}\text { No } \\
\text { encapsulation }\end{array}$ & $\begin{array}{l}\text { Capacitors } \\
\text { encapsulated }\end{array}$ \\
\cline { 2 - 5 } $\mathrm{Ag}-\mathrm{Pt}$ & 130 & 40 & 100 & 3000 \\
$\mathrm{Ag}-\mathrm{Pd}$ & 310 & 100 & 90 & 2800 \\
$\mathrm{Ag}-\mathrm{Pd}-\mathrm{Pt}$ & $>4000$ & 890 & 960 & $>4000$ \\
$\mathrm{Au}-\mathrm{Pd}$ & $>4000$ & 480 & 870 & $>4000$ \\
$\mathrm{Au}-\mathrm{Pt}$ & $>4000$ & 530 & 980 & $>4000$ \\
$\mathrm{Au}$ & $>4000$ & 360 & 760 & $>4000$ \\
$\mathrm{Cu}$ & 960 & 720 & - & - \\
$\mathrm{Ag}-\mathrm{Pd}-\mathrm{Pt}$ & 730 & 460 & - & - \\
soldered & & & & \\
$(60 \mathrm{Sn} / 40 \mathrm{~Pb})$ & & & & \\
\hline
\end{tabular}

sition. It had a relative long life time even in the case of $\mathrm{Cl}^{-}$contaminated surfaces. It was the bismuth migration that caused short circuits at the capacitors with nonmigrating electrodes. Encapsulated capacitors showed enhanced reliability. As can be seen, the experiences of the THB test have confirmed and completed those of the Water Drop test.

\section{METHODS OF PROTECTION}

Our experiments demonstrated that the importance of electro-chemical migration must be recognised in almost all thick-film conductor-insulator-conductor systems. Thus the question of an effective protection naturally arises and is the subject of present research work. The main problems and possible solutions are summarized below.

(i) It is advisable to use non-migrating conductors in high-reliability circuits. One would like to re-emphasize attention to the advantages of ternary $\mathrm{Pd}-\mathrm{Pt}-\mathrm{Ag}$ conductors which - with favourable compositions - have relative long life times (see Table I) even on surfaces contaminated with $\mathrm{Cl}^{-}$ions.

(ii) The other possibility of protection is by preventing moisture from penetrating to the device surface.

Hermetically sealed packages give the best protection. It has been reported, however, that the glass-to-metal seals used in many of the packages do not remain hermetic during thermal excursions. ${ }^{6}$ Using metal-to-metal seals, moisture adsorbed on the surfaces of the package parts can be the primary source of package contamination. This moisture must be removed by the use of bakeout procedures. ${ }^{6}$ The great disadvantage of the hermetically sealed packages is that they are very expensive. It is well known that plastic packages do not give a proper protection from moisture, and therefore the use of different encapsulants is necessary. It has been demonstrated ${ }^{7}$ that the screen printable overglazes used for resistors are not suitable for this purpose because there are a lot of defects in these layers. Therefore the paste manufacturers have developed screenprintable crystallizable glasses for capacitor-over-glazes. ${ }^{8}$ It is not sufficient to use one 
overlayer, the use of double-layers, or one amorphous and one crystallizable layer, is necessary to achieve the required reliability. Thus the number of printing-firing cycles becomes large. Another drawback of this method is that the solder pads cannot be protected. An ideal overcoating system would be one which could be applied after component mounting so that it could also prevent the components of the solder, $\mathrm{Pb}$ and $\mathrm{Sn}$, from migrating. An ideal coating should not need a firing process of over $120^{\circ} \mathrm{C}$ because a higher temperature causes ageing of the soldered conductors. Additional requirements are that the coating must not destroy the bonded wires or cause deterioration of the long term stability of the trimmed resistors. Silicone RTV materials seem to be the most appropriate materials to use because they are non-corrosive, chemically inactive, elastic and give a good protection from moisture. Good results have been reached when using the Dow Corning 36550 type. (See Table I).

Last, but not least, one must mention the importance of the pre-encapsulation cleaning process. This must remove not only the organic contaminants and inorganic salts - especially chloride ions - but the adsorbed water molecules as well.

\section{CONCLUSIONS}

Water drop migration tests have been performed on different conductor-insulator systems used in thick-film circuits. Using a scanning electron microscope, elemental X-ray mapping has shown that resistive shorts can be caused by the migration of the following elements: $\mathrm{Ag}, \mathrm{Pb}, \mathrm{Sn}, \mathrm{Cu}, \mathrm{Au}, \mathrm{Pd}, \mathrm{Pt}, \mathrm{Bi}$.

$\mathrm{Au}, \mathrm{Pd}, \mathrm{Pt}$ migrate only in the case of $\mathrm{Cl}^{-}$contaminated substrates. Bismuth migration occurs only in thick-film capacitors using $\mathrm{Bi}_{2} \mathrm{O}_{3}$ containing dielectrics.

THB tests have also been conducted to make a comparison between the different conductor compositions. It proved that favourable Ag-Pd-Pt compositions were the most reliable systems because they had relative long life times even in the case of $\mathrm{Cl}^{-}$ contaminated surfaces. The applied silicone encapsulant had great effectiveness in preventing migrated resistive shorts.

Thus the probability of migrated resistive shorts can be decreased by the use of:

- migration resistive conductors,

- waterproof encapsulants before packaging,

- appropriate cleaning methods to avoid $\mathrm{Cl}^{-}$contamination.

\section{REFERENCES}

1. G.T. Kohman, H.W. Hermance and G.H. Downes, "Silver Migration in Electrical Insulations" Bell System Technical Journal 34 pp. 1115-1147, (1955).

2. A. DerMarderosian, "The Electrochemical Migration of Metals", Proceedings of ISHM Symposium pp. 134-136, (1978).

3. N.L. Sbar, "Bias-Humidity Performance of Encapsulated and Unencapsulated Ti-Pd-Au Thin-Film Conductors in an Environment Contaminated with $\mathrm{Cl}_{2}$, IEEE Transactions on Parts, Hybrids and Packaging PHP-12 (1976).

4. P. Benes, "On the State of Manganese and Gold Traces in Aqueous Solutions", J. Inorg. Nucl Chem. 29 pp. 2889-2898 (1967).

5. L.C. Hoffman and T. Nakayama, "Screen Printed Capacitor Dielectrics", Microelectronics and Reliability 7 pp. $131-135$ (1968).

6. R.W. Thomas, "Moisture, Myths and Microcircuits", IEEE Transactions on Parts, Hybrids and Packaging PHP-12 pp. 167-171 (1976).

7. M.V. Coleman and A.E. Winster, "Silver Migration in Thick-Film Conductors and Chip Attachment Resins", Microelectronics Journal 12 No. 4, pp. 23-29 (1981).

8. K. Abe, A. Ikegami, N. Sugishita, N. Taguchi, T. Isogai, I. Tsubokava and H. Ohtsu, "Development of the Thick-Film Capacitor and Its Application for Hybrid Circuit Modules", IEEE Transactions on Components, Hybrids and Manufacturing Technology CHMT-2 pp. 434-440 (1979). 

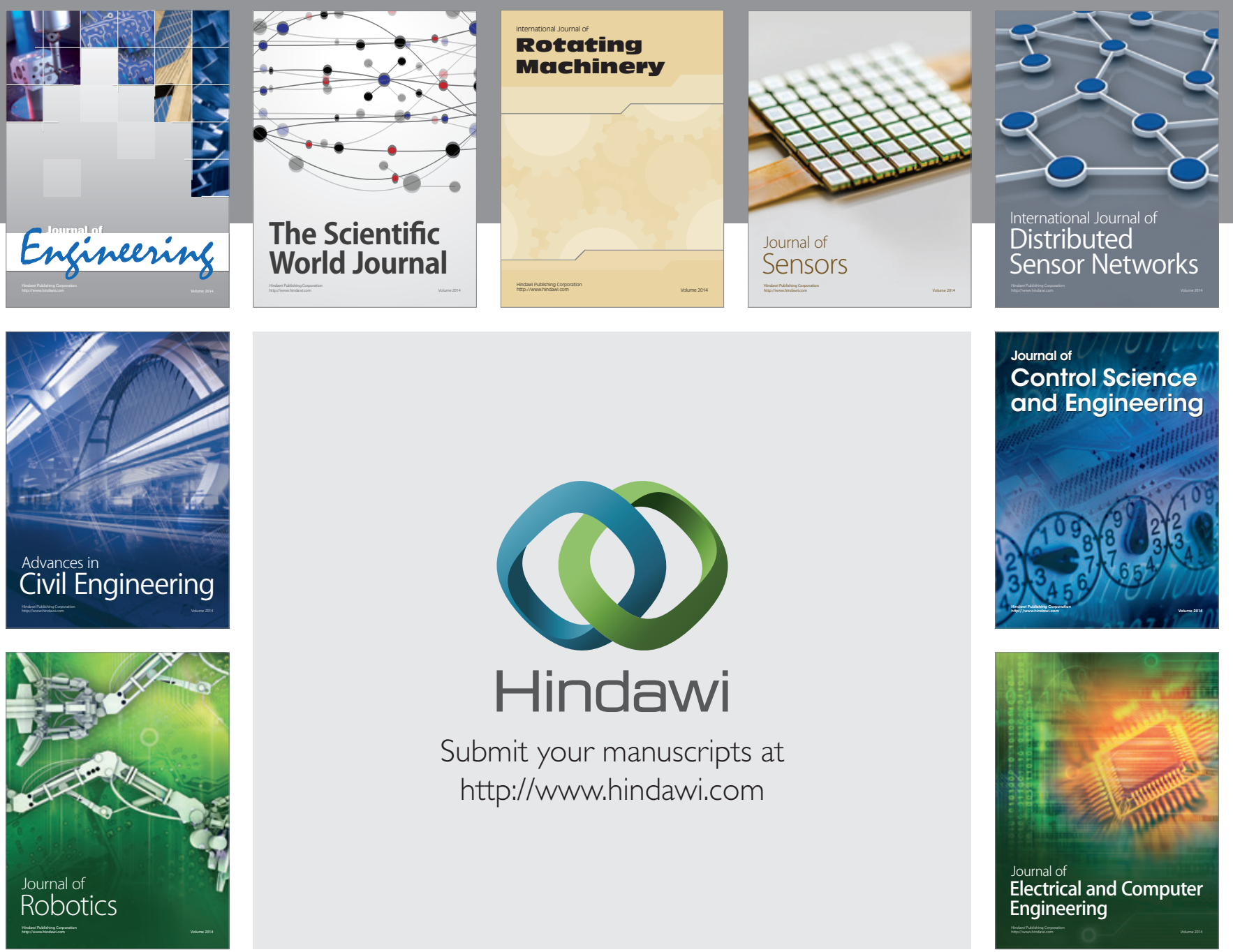

Submit your manuscripts at

http://www.hindawi.com
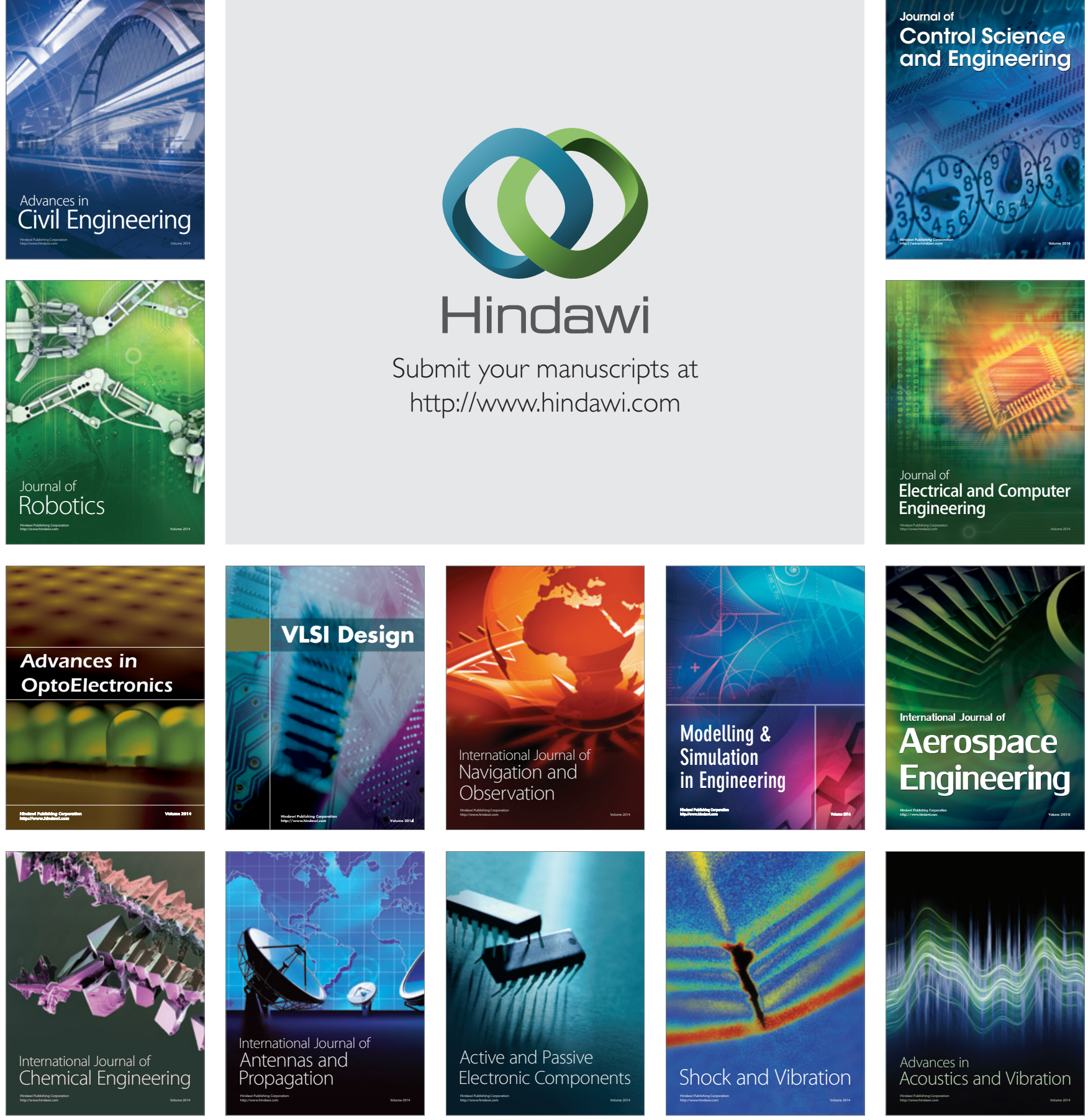